\title{
Set size and order requirements in immediate memory*
}

\author{
JAMES V. HINRICHS and GAIL McKOON $\dagger$ \\ University of Iowa, lowa City, Jowa 52240
}

\begin{abstract}
Three types of order requirements in the immediate recall of number sequences were investigated in two experiments. Experiment I examined written recall and Experiment II spoken recall. Natural serial recall was found to be superior to same order and free recall (a) in Experiment I because repeated correct intrusions were reduced, and (b) in Experiment II because more responses were produced. Implications for the analysis of mnemonic devices were briefly introduced.
\end{abstract}

At least three different recall order requirements can be distinguished in immediate memory experiments employing short sequences of homogeneous material: same order recall, natural serial recall, and free recall. Requiring same order recall is clearly the most stringent of the three: $S$ is required to remember the items in exactly the same order as they were presented. In free recall, no recall order is imposed upon $S$; he is free to recall the items in any order he wishes. However, the use of free recall procedure does not eliminate a recall order requirement. Even though no specific order is specified, $S$ still must recall the items in some order; the order, however, is self-imposed rather than experimenter-imposed. The natural serial recall order would appear to be immediate between same order and free recall requirements. In the natural serial recall method, Ss are required to produce the items in their natural ascending sequential order, such as numbers in cardinal order or letters in alphabetical order. Therefore, an order requirement is imposed upon $\mathrm{S}$, but the order is well known and overlearned.

Comparison of natural serial recall with free recall and same order recall raises some questions about expected degree of difficulty. On the one hand, natural serial recall might be expected to be superior to same order recall but inferior to free recall because retention of order information is required but the particular order is very well learned and known to $S$ s in advance. On the other hand, natural serial recall might be expected to be superior to free recall because it provides an efficient organization upon which to base later retention. In fact, Buschke and Hinrichs (1968) found little difference between natural serial and free recall, although both were superior to either forward or backward recall orders. Their study was restricted to 10 -item sequences,

*This research was supported by Grant MH-16362 from the National Institute of Mental Health. The second author was a member of the Undergraduate Research Participation program supported by National Science Foundation Grant GY6113.

$\div$ Now at the University of Colorado. Boulder, Colorado 80302. and performance was very high in both natural serial and free recall conditions. Therefore, one purpose of the present series of experiments was to explore natural serial and free recall over several set sizes and restrictions in production order to distinguish any possible differences in retention.

Hinrichs and McKoon (1971) demonstrated that order and number requirements play an important role in distinguishing between natural serial and same order retention. Depending upon the number of responses required, the order of production of the responses and the modality of the responses may both influence the retention of order information. For example, when Ss are allowed to use spoken recall, the free recall procedure would appear to have an important advantage. With spoken recall, Ss may produce the responses in any order they please in the free recall condition. However, in natural serial and same order recall, the items must be produced in a particular final order. In other words, with spoken recall, production order and final protocol order must be identical. However, with written recall, production order and the final recall order need not be identical. Unless otherwise restricted, Ss have the option of producing their responses in any order they choose. Therefore, another goal of the present.research was to consider the role of restrictions in production order for retention of order information. Consequently, both written and oral recall methods were investigated in separate experiments.

\section{EXPERIMENT I}

\section{Method}

\section{Subjects and Design}

The Ss were 54 members of introductory psychology classes at the University of lowa who fulfilled a course requirement by participating in the experiment. All Ss were tested in groups of two or three individuals and were screened from each other's view during the experiment. The $\mathrm{S} s$ were assigned to one of three recall groups, 18 Ss per group, according to a prearranged assignment schedule. The recall groups differed according to the required order of recall: same order-the same order as the items were presented: natural serial-the items were required to be 
Table 1

Order and Type of Responses: Experiment I

\begin{tabular}{|c|c|c|c|c|c|c|c|c|}
\hline \multirow{2}{*}{ 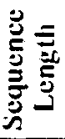 } & \multirow[b]{2}{*}{$\begin{array}{l}\text { Recall } \\
\text { Order }\end{array}$} & \multicolumn{2}{|c|}{ Ascending Pairs } & \multicolumn{2}{|c|}{ Correct } & \multicolumn{3}{|c|}{ Mean Errors } \\
\hline & & Mean & SE & Mean & $\mathrm{SE}$ & $\begin{array}{c}\text { Repeated } \\
\text { Correct }\end{array}$ & $\begin{array}{l}\text { Intru- } \\
\text { sions }\end{array}$ & $\begin{array}{l}\text { Repeated } \\
\text { Intrusions }\end{array}$ \\
\hline 10 & $\begin{array}{l}\text { NS } \\
\text { FR } \\
\text { SO }\end{array}$ & $\begin{array}{l}8.872 \\
5.150 \\
4.700\end{array}$ & $\begin{array}{l}.040 \\
.226 \\
.079\end{array}$ & $\begin{array}{l}6.967 \\
6.783 \\
6.461\end{array}$ & $\begin{array}{l}.078 \\
.118 \\
.129\end{array}$ & $\begin{array}{l}.006 \\
.244 \\
.628\end{array}$ & $\begin{array}{l}3.022 \\
2.911 \\
2.800\end{array}$ & $\begin{array}{l}.006 \\
.061 \\
.111\end{array}$ \\
\hline 15 & $\begin{array}{l}\text { NS } \\
\text { FR } \\
\text { SO }\end{array}$ & $\begin{array}{r}13.683 \\
8.522 \\
7.650\end{array}$ & $\begin{array}{l}.129 \\
.351 \\
.178\end{array}$ & $\begin{array}{l}9.744 \\
9.417 \\
8.722\end{array}$ & $\begin{array}{l}.117 \\
.236 \\
.185\end{array}$ & $\begin{array}{r}.022 \\
.506 \\
1.217\end{array}$ & $\begin{array}{l}5.228 \\
4.911 \\
4.717\end{array}$ & $\begin{array}{l}.006 \\
.167 \\
.344\end{array}$ \\
\hline 25 & $\begin{array}{l}\text { NS } \\
\text { FR } \\
\text { SO }\end{array}$ & $\begin{array}{l}23.628 \\
14.494 \\
13.639\end{array}$ & $\begin{array}{l}.139 \\
.486 \\
.364\end{array}$ & $\begin{array}{l}14.544 \\
13.594 \\
12.633\end{array}$ & $\begin{array}{l}.210 \\
.229 \\
.307\end{array}$ & $\begin{array}{r}.039 \\
1.328 \\
2.544\end{array}$ & $\begin{array}{r}10.411 \\
9.544 \\
8.806\end{array}$ & $\begin{array}{r}.006 \\
.533 \\
1.017\end{array}$ \\
\hline
\end{tabular}

arranged into their numerical ascending order: and free recall-no resfonse order was specified. Within each recall group, three sequence lengths were presented. Ten sequences of 10.15 , and 25 numbers were presented in three blocks with order of administration of the blocks counterbalanced across Ss.

\section{Materials}

Each presented sequence consisted of a series of two-digit numbers chosen from a set size exactly twice the length of the presented sequence. The 10 -item sequences consisted of 10 numbers from the set of 20 numbers from 21 to 40 inclusive; the 15 -item sequences consisted of 15 numbers from the 30 -member set from 21 to 50 : and the 25 -item sequence consisted of 25 numbers from the 50 -item set from 21 to 70 . The numbers in each sequence were chosen randomly from the designated set with the constraint that no number could appear more than once within each sequence. The same set of 30 sequences was used for all Ss.

\section{Procedure}

The numbers were presented aurally via a tape recorder at a 1-item/sec rate with the beginning and the end of each sequence signaled $b y$ a tone. After the tone at the end of the sequence, Ss recalled the numbers by writing them in boxes on answer sheets with the number of boxes provided for each sequence equal to the number of items in the presented sequence. In the same order condition. Ss were required to list the first number presented in the first box, the second in the second box, and so forth. In the free recall condition. Ss could place any number in any box. In the natural serial condition. Ss were instructed to list the smallest presented number in the first box, the second smallest number in the second box, and so forth. In all recall conditions, Ss were required to list as many numbers as were presented. guessing whenever necessary. The order of production of the responses was not specified so that $S s$ were permitted to begin listing responses in any response box and could skip from any box to any other box. Although the Ss were strongly instructed not to deviate from the required recall order, responses out of order were accepted in order to equate response opportunity among the three conditions.

\section{Results}

In scoring recall sequences, order was disregarded for all three recall conditions. A presented item was counted correct if it appeared in the response sequence regardless of its position. Consequently, order of recall did not influence the scoring method. although it was varied in the recall instructions. If a correct number appeared more than once in a response sequence, it was scored as a correct response on the first occasion but not thereafter. An analysis of the response sequences and the type of responses produced by $\mathrm{Ss}$ is presented in Table 1, where the mean number of correct and corresponding standard errors of the mean, the mean number of repeated correct responses, the mean number of intrusions, and the mean number of repeated intrusions are presented for each condition.

\section{Response Order}

A comparison of the type of ordering produced by Ss is also presented in Table 1 in the column labeled "Ascending Pairs." Ascending pairs refer to the frequency with which two successive numbers in the response protocol occur in their ascending natural serial order. For each sequence length, the maximum possible score is one less than the sequence length. Hence, for the 10-item sequences, there are nine possible ascending pairs in the perfect natural serial recall protocol. As shown in Table 1, the natural serial condition Ss almost always produced their items in perfect ascending order. The chance level for the number of ascending pairs would be approximately one-half the number of possible ascending pairs. The actual mean number of ascending pairs in the presented sequences for each of the 10-, 15., and 25 -item recall sequences was $4.40,7.20$, and 13.00 , respectively.

A 3 by 3 analysis of variance with recall order as a between-S factor and set size as a within-S factor was conducted on the ascending pairs data. The set size factor was significant, of course $[F(2,102)=2989.61$, $\mathrm{p}<.001]$, as was the recall order factor $[F(2,51)=$ 263.92, $\mathrm{p}<.001]$ and their interaction $[\mathrm{F}(4,102)=$ $88.54, \mathrm{p}<.001]$. The number of ascending pairs in the same order condition was only slightly higher than the number of presented ascending pairs and significant only in the 10-item sequences $(p<.01)$. The number of ascending pairs in the natural serial condition was slightly but consistently less than the expected number. 
assuming perfect natural serial ordering, for all sequence lengths ( $\mathrm{p}<.025$ in all cases). The most interesting comparison occurs with respect to the free recall sequences. If free recall Ss adopted a natural serial order recall strategy, then the number of ascending pairs should begin to approximate those observed for the natural serial Ss. However, as shown in Table 1, the number of ascending pairs produced by the free recall Ss most clearly approximates those produced by the same order recall Ss. The number of ascending pairs in the free recall condition is much smaller than in the natural serial recall condition ( $p<.001$ for all set sizes) and nonsignificantly larger than in the same order condition ( $>.05$ for all set sizes). Inspection of the response sequences also indicates the adoption of same order recall by the free recall $S s$ and little evidence of a natural serial order recall strategy.

\section{Retention Performance}

As would be expected, the number of correct responses differs markedly across the three presented sequence lengths. This result is not interesting because it follows immediately from the difference in the number of responses to be produced in each condition. Consequently, by chance alone a difference among the three conditions would be expected. A more suitable basis for comparison exists when the response protocols in the three conditions are equated by subtracting the number of correct responses to be expected by chance. When this is done, significant sources of variance are contributed by recall order $[\mathrm{F}(2,51)=14.36, \mathrm{p}<.001]$, by set size $[F(2,102)=19.20, p<.001]$, and by the Recall Order by Set Size interaction $[F(4,102)=5.41$, $p<.011$. As shown in Table 1, the natural serial order Ss maintain a consistent two-item advantage above chance across all three sequence lengths. However, the free recall and same order Ss both show a decline across sequence length in the number of items recalled above chance. In fact, for Set Size 25 in the same order condition, recall performance does not differ significantly from chance $(t<1)$. Specific contrasts reveal that natural serial and free recall performance differs only for Set Size $25(p<.001$, with $p>.10$ for the other two set sizes). The same order and free recall conditions are significantly different $(p<.01)$ except in the smallest set size $(p>.10)$. By inspection of $T$ able 1 , it is clear that at least a major portion of the advantage of natural serial recall over free recall and certainly of natural serial recall over same order recall is due to the small number of repeated correct responses which occur in the natural serial order condition.

\section{EXPERIMENT II}

\section{Method}

\section{Subjects and Design}

The Ss were 36 undergsaduates attending the liniversity of
Iowa summer school, and all were between 18 and 26 years of age inclusive. The Ss were paid for their participation in the experiment and were tested individually. The materials and design were identical to those used in Experiment I, except that 12 Ss were assigned to each recall condition.

\section{Procedure}

All procedural details in Experiment II were identical to those used in Experiment I, except that in Experiment II Ss were tested individually and were required to recall each sequence orally. The number of responses to be produced was not specified, but Ss were encouraged to guess.

\section{Results}

Again, recall order was disregarded in scoring all three recall conditions. An analysis of the responses produced by $S s$ is presented in Table 2 . The major difference between Experiment I and Experiment II appears to occur as a result of the greater number of responses produced in the natural serial order recall condition in Experiment II. Only in the natural serial condition did Ss produce almost as many responses as presented items. Consequently, except in the natural serial condition, Ss often scored below chance even though guessing was encouraged. As a result, the main effects of recall order and set sizes were again significant sources of variance $[F(2,33)=15.97, p<.001$ and $F(2,66)=89.68$, $\mathrm{p}<.001$, respectively]. The significant Recall Order by Set Size interaction $[F(2,66)=4.44, p<.01]$ indicates that the difference between the recall order conditions became larger as the set size increased. The intrusion rate was also much higher for the natural serial condition than for the other two conditions, further suggesting that natural serial Ss were more willing to produce responses than were $S s$ in the other two conditions.

The contribution of the effect of number of responses produced can be reduced by scoring each $S$ in terms of the proportion of correct responses relative to the number of responses emitted. When this is done, the effect of set size is still significant $[F(2,66)=24.62$. $\mathrm{p}<.001]$, but the recall order effect is not significant $[F(2,33)<1]$, nor is their interaction $[F(2,66)=1.69$, $\mathrm{p}>.10]$.

\section{DISCUSSION}

The results indicate a clear ordering of relative recall performance under three types of response order instructions. natural serial recall $>$ free recall $>$ same order recall. The same relative ordering of performance was obtained with both written and spoken recall when the number of responses produced was controlled in written recall but could vary in spoken recall. However. the results also indicate that two different but related factors may be responsible for the superior natural serial recall performance under the two response methods.

In the case of spoken recall. a primary source of the advantage of natural serial recall stens from the simple difference in the number of responses produced. 
Table 2

Type of Responses: Experiment II

\begin{tabular}{|c|c|c|c|c|c|c|c|}
\hline \multirow[b]{2}{*}{$\begin{array}{c}\text { Sequence } \\
\text { Length }\end{array}$} & \multirow[b]{2}{*}{$\begin{array}{l}\text { Recall } \\
\text { Order }\end{array}$} & \multicolumn{2}{|c|}{ Correct } & \multicolumn{4}{|c|}{ Mean Errors } \\
\hline & & Mean & SE & $\begin{array}{c}\text { Repeated } \\
\text { Correct }\end{array}$ & Intrusions & $\begin{array}{l}\text { Repeated } \\
\text { Intrusions }\end{array}$ & Omissions \\
\hline 10 & $\begin{array}{l}\text { NS } \\
\text { FR } \\
\text { SO }\end{array}$ & $\begin{array}{l}7.058 \\
5.725 \\
5.142\end{array}$ & $\begin{array}{l}.212 \\
.168 \\
.305\end{array}$ & $\begin{array}{l}.000 \\
.225 \\
.325\end{array}$ & $\begin{array}{l}2.092 \\
1.558 \\
1.550\end{array}$ & $\begin{array}{l}.000 \\
.025 \\
.075\end{array}$ & $\begin{array}{r}.850 \\
2.467 \\
2.908\end{array}$ \\
\hline 15 & $\begin{array}{l}\text { NS } \\
\text { FR } \\
\text { SO }\end{array}$ & $\begin{array}{l}8.317 \\
6.983 \\
5.933\end{array}$ & $\begin{array}{l}.437 \\
.367 \\
.396\end{array}$ & $\begin{array}{l}.008 \\
.300 \\
.358\end{array}$ & $\begin{array}{l}4.167 \\
2.717 \\
2.317\end{array}$ & $\begin{array}{l}.000 \\
.042 \\
.142\end{array}$ & $\begin{array}{l}2.508 \\
4.958 \\
6.250\end{array}$ \\
\hline 25 & $\begin{array}{l}\text { NS } \\
\text { FR } \\
\text { SO }\end{array}$ & $\begin{array}{r}12.050 \\
8.692 \\
7.650\end{array}$ & $\begin{array}{l}.740 \\
.768 \\
.395\end{array}$ & $\begin{array}{l}.067 \\
.358 \\
.600\end{array}$ & $\begin{array}{l}7.225 \\
3.758 \\
3.317\end{array}$ & $\begin{array}{l}.000 \\
.067 \\
.225\end{array}$ & $\begin{array}{r}5.658 \\
12.125 \\
13.208\end{array}$ \\
\hline
\end{tabular}

Although all groups were urged to guess and no penalty was invoked for erroneous guesses, Ss in the free recall and the same order recall groups produced markedly fewer responses than $S$ s in the natural serial recall group. The tendency was especially pronounced with larger set sizes. All recall groups had approximately the same proportion of correct responses in their response protocols: natural serial Ss simply produced more responses.

In written recall. where all $S s$ were required to produce the same number of responses, natural serial recall performance was still generally superior to free recall and same order recall. Here, however, the advantage of natural serial recall-and, to a lesser extent, of free recall-was to be found in the reduced number of repeated correct responses and intrusions, especially repeated intrusions (cf. Table 1). Apparently, the natural serial recall method prevents the production of repeated responses, thereby increasing the likelihood of producing other, correct responses.

Taken together. the results of the two experiments suggest that the superiority of natural serial recall is due not to any difference in associative factors or memory strength per se. but rather to differences in efficiency in organizing or controlling response production. The natural serial recall method allows an easy means of scanning or checking the set of possible responses and determining whether or not each item was in the presented set (cf. Buschke \& Hinrichs. 1968). In short, the natural serial recall method closely resembles a recognition procedure. A similar advantage is available to Ss using the free recall method, but only if Ss use some system for organizing their responses which permits each possible response to be examined once and only once. In fact, however, analysis of the ascending pairs produced in Experiment I suggests that the most typical free recall protocol was very similar to a same order recall protocol.
Furthermore, as the size of set of presented items (and required responses) increases, the burden of organizing the response protocol also increases, resulting in a still greater advantage of natural serial recall.

Although the present experiment was concerned only with the recall of sequences of familiar homogeneous items. it is of some interest to consider the implications of the results for some recent discussions of mnemonic devices. For example, Bower (1970) has emphasized the organizational and cueing properties of various mnemonic schemes, and most of the research investigating these properties has employed materials that obviously capitalize on these characteristics. e.g., high imagery value or networks of interassociations. Nevertheless, the present results suggest that similar effects may be obtained using common materials with very different properties. Furthermore, it may well be the case that at least part of the retention facilitation produced by various mnemonic schemes occurs for the same reasons as the advantage of natural serial recall over free recall and same order recall. Specifically, retention may be enhanced by any recall method which both increases the number of responses produced and decreases the number of response repetitions.

\section{REFERENCES}

Bower. G. H. Analysis of a mnemonic device. American Scientist, $1970,58,496-510$.

Buschke, H., \& Hinrichs, J. V. Controlled rehearsal and recall order in serial list retention. Journal of Experimental Psychology, 1968, 78, 502-509.

Hinrichs, J. V., \& McKoon, G. Order and number requirements in immediate serial recall. Journal of Experimental Psychology, 1971, 87, 215-220.

(Received for publication September 1, 1972; revision received October 9,1972 .) 